\title{
GUIDE FOR AUTHOR
}

\author{
AUTHOR GUIDELINES \\ Author Guidelines for Manuscript Preparation
}

\section{Type of paper}

Research papers, state-of-the art review and short communication are accepted which have not been submitted and would not be submitted elsewhere.

\section{Preparation of Manuscript}

Authors must abide by the author guidelines of this journal. Figure (s) and table (s) must be separated from text but still in one file (Single file). Authors must upload a cover letter together with the main document.

\section{Language}

Manuscript must be written in academic Indonesian Language or English. Author (s) who is not native English speaker is recommended to ask English native speakers to check the used language including spelling and grammar. For those who use Indonesian language are also recommended to check the used words in KBBI (Kamus Besar Bahasa Indonesia) and or Ministry of Education Regulation No.49 year of 2009 on standardized spelling.

\section{Originality}

The manuscript must be an original work. Authors are recommended to use plagiarism checking program (TURNITIN) to check the similarity from prior publication. Once the similarity $\leq 30 \%$, the paper is passed for further consideration, manuscript with the similarity exceeding $30 \%$ will be rejected.

\section{Title Page Information}

Title - Concise and should be written in the form of lower-case with capitalization of the first word. Title must be written in Indonesian Language and English 
Author names and affiliations - Please correctly write the author and co-author name, then indicate all affiliations with alphabets superscripts after the author's name and in front of the appropriate address unless the author (s) from the same affiliation. Please provide full postal address of each affiliation.

Corresponding author - Clearly indicate who with $\left(^{*}\right)$ after superscript indicating affiliation and only the e-mail address of the corresponding author is allowed.

Note: text in the title page must be left.

\section{Manuscript Style}

Manuscripts are prepared on A4 paper size, should be double-spaced and typed using 12 point Times New Roman of equivalent typeface with a margin of $4 \mathrm{~cm}$ (1.5 inch) on all four sides. Text must be set in left and the line must be numbered.

\section{The manuscript contains}

a) Abstract- must consecutively contain the brief outline of the problem solved, the objective of the study, brief research methodology, including the used experimental design, the result of the study, conclusion and suggestion for further research (if any). Abstract does not exceed 250 words

b) Keywords - the number of used keyword is 3-6 words indicating the crucial words of the whole study report. Keywords must be separated with comma.

c) Introduction - It must be concise, containing the problem intended to be solved, the research gap, and the objective of the study and the outcome of the study (if any). Introduction must be completed with appropriate references.

d) Materials and Methods - only crucial techniques are described. The referenced methods must be completed with the citation, if the method is modified, please state the modification. The used equipment must be specified with the trademark and type, materials used must be showed with the supplier name and the country.

e) Result and Discussion - result and discussion must be combined. Results must be clear and concise and explained its significance in the discussion

f) Conclusion - It summarizes the result and answers the research question/objective. Repetition of the discussion is highly forbidden. If any suggestion of the research, it can also be outlined in this part

g) Acknowledgement - Only people or institution that help to succeed the research such as the funding, volunteer, or proof reader. 


\section{h) Reference}

1. The citation in text and bibliography are Harvard APA style

2. References must contain $80 \%$ journal article and $\leq 20 \%$ other sources

3. Author (s) is recommended to use reference manager such us EndNote and MENDELEY

4. References should be placed in alphabetical order by surname of author/s

a. If there are two or more references to the same author, they should be presented in chronological order with the earliest reference presented first

b. If there are two or more references to the same author in the same year, they should be distinguished by adding a, b, c, etc. after the year of publication.

The style of presenting a bibliographic reference varies according to the type of reference. Below are details of how to present the most common types of material as bibliographic references.

\section{Books}

Haynes, J. (2005). Comparative politics in a globalizing world. Cambridge: Polity.

Kubálková, V., Onuf, N., \& Kowert, P. (Eds.). (1998). International relations in a constructed world. Armonk, NY: M. E. Sharpe.

Marr, P. (2004). The modern history of Iraq (2nd ed.). Boulder, CO: Westview.

Name of author/s or editor/s using last name, plus initial/s. (Type Ed. or Eds. - short for editor/s- here if referring to a whole edited book). (Year of publication). Title of Book (Edition number goes here if later than first e.g. 2nd ed.). Place of publication: Publisher.

\section{Electronic books}

Gordon, P. H., \& Shapiro, J. (2004). Allies at war: America, Europe and the crisis over Iraq [Electronic version]. New York: McGraw-Hill.

This format is identical to that of a printed book apart from adding "Electronic version" in Square brackets immediately after the book title. 


\section{Chapters in edited books}

Evans, T. (1997). Democratization and human rights. In A. McGrew (Ed.), The transformation of democracy? (pp. 122-148). Cambridge: Polity Press.

Name of author. (Year of publication). Title of chapter. In Name of editor/s (Ed/s.), Title of book ( $\mathrm{pp}$. Start and end page numbers of chapter). Place of publication: Publisher.

\section{Journal articles}

Foster, C. D. (2001). The civil service under stress: the fall in civil service power and authority. Public Administration, 79(3), 725-749.

Name of author/s. (Year of publication). Title of article. Title of Journal, Volume number (issue number), Start and end page numbers of article.

\section{Magazine articles}

Hobsbawm, E. (1998, November/December). The death of neo-liberalism. Marxism Today, 4-8.

Name of author/s. (Year of publication, Date of publication - month/s or month plus day if weekly). Title of article. Title of Magazine, Page number/s of article.

\section{Newspaper articles}

Cowan, R. (2001, October 23). Adams asks IRA to disarm. The Guardian, p. 1.

Name of author/s. (Year of publication, Date of publication - month plus day). Title of article. Title of Newspaper, Page number/s of article.

\section{Official publications}

Prime Minister's Office \& Cabinet Office. (1999). Modernising Government (Cm 4310). London: The Stationery Office. 
Select Committee on Defence. (1996). Fourth Report, Westland plc: The Government's Decision-Making (HC 519). London: HMSO.

Name of author/s. (Year of publication). Title of Official Publication (Official publication's reference number). Place of publication: Publisher.

\section{Conference papers}

Newman, J. (2001, September). New Labor and the Politics of Governance. Paper presented at the Annual Conference of the European Group of Public Administration, Vaasa, Finland.

Name of author/s. (Year of publication, Month of conference). Title of Conference Paper. Paper presented at the Title of Conference or the Name of the Organization holding the conference, Location of conference.

\section{Website material}

Commission of the European Communities. (2001). Governance in the European Union: a White Paper. Retrieved August 21, 2001, from http://europa.eu.int/governance/white_paper/index_en.htm

Name of author/s. (Year of publication). Title of web page. Retrieved date accessed, from World Wide Web address.

\section{Tables, Graphs, Figures and Photographs}

Tables, graphs and figures should be displayed on separate pages in black and white in the manuscript after the reference section. Tables and figures should be numbered consecutively in accordance with their appearance in the text. Tables are captioned on top of the table body and place any table notes below the table body with proper indications to the contents in the table body (if needed). Figures are captioned at the bottom of the figures. Scanned or digital photographs should be in high resolution, minimum $300 \mathrm{dpi}$ in the PC format. A maximum of 5 Figures and Tables is only allowed; hence, be sparing (unless state of the art review).

\section{Equation}

Equation must be clearly informed while using symbol and numbered. 


\section{Miscellaneous}

a) Decimal must be expressed as comma (,) while using Indonesian Language and dot (.) while using English

b) Do not use '\&' to indicate 'and'

c) Do not use uncommon abbreviation. Any abbreviation should be stated in brackets next to the full name at the beginning of the text before proceeding to use the abbreviation

d) Space is not allowed after number, prior unit $(1 \mathrm{~g}, 1 \%(\mathrm{w} / \mathrm{w}), 2 \mathrm{~N})$

e) Do not make columns while preparing manuscripts

f) Do not follow the writing style of published paper, but follow the guideline of preparing manuscript

\section{SUBMISSION PREPARATION CHECKLIST}

As part of the submission process, authors are required to check off their submission's compliance with all of the following items, and submissions may be returned to authors that do not adhere to these guidelines.

1. The submission has not been previously published, nor is it before another journal for consideration (or an explanation has been provided in Comments to the Editor).

2. The submission file is in OpenOffice, Microsoft Word, RTF, or WordPerfect document file format.

3. Where available, URLs for the references have been provided.

4. The text is single-spaced; uses a 12-point font; employs italics, rather than underlining (except with URL addresses); and all illustrations, figures, and tables are placed within the text at the appropriate points, rather than at the end.

5. The text adheres to the stylistic and bibliographic requirements outlined in the Author Guidelines, which is found in About the Journal.

6. If submitting to a peer-reviewed section of the journal, the instructions in Ensuring a Blind Review have been followed.

\section{COPYRIGHT NOTICE}

1. Copyright of this journal is possession of Editorial Board and Journal Manager, by the knowledge of author, whilst the moral right of the publication belongs to the author. 
2. Legal formal aspect of journal publication accessibility refers to Creative Commons Atribusi-Non Commercial-No Derivative (CC BY-NC-SA),implies that publication can be used for non-commercial purposes in its original form.

3. Every publications (printed/electronic) are open access for educational purposes, research, and library. Other that the aims mentioned above, editorial board is not responsible for copyright violation

\section{PRIVACY STATEMENT}

The names and email addresses entered in this journal site will be used exclusively for the stated purposes of this journal and will not be made available for any other purpose or to any other party. 